\title{
Asymptomatic Cervical Isthmic Spondylolisthesis and Associated Occult Spinal Bifida: A Case Report -
}

\author{
Jeong-Wook Lim¹, Sang-Kuk Kang ${ }^{2}$, Su-Gi Jeon ${ }^{1}$, Byeong-Chul Lim ${ }^{1}$ \\ ${ }^{1}$ Departments of Neurosurgery, ${ }^{2}$ Rehabilitation Medicine, Daejeon Sun Hospital, Daejeon, Korea
}

We report a case of rare cervical isthmic spondylolisthesis of C6-7 combined occult spinal bifida at C6, and review the radiologic finding, different diagnosis and treatment. A 23-year old female presented nuchal, back pain after traffic accident. Radiologic finding showed the $6^{\text {th }}$ cervical isthmic defect, spondylolisthesis and dysplasia. The patient was conservatively treated about 8 weeks, and 10 months after injury, she was symptom free with full range of motion of cervical spine and she was followed up. Cervical spondylolysis is a very rare condition. This clinical importance is vulnerable to trauma. For whatever reasons, symptomatic patients need to be treated by conservative or surgical option.

Key Words: Cervical Vertebrae, Spondylolysis, Spondylolisthesis, Spinal bifida

\section{INTRODUCTION}

Cervical spine spondylolysis is the most commonly caused by high energy trauma to the upper cervical spine in the form of a "hangman's" fracture of C2 vertebrae ${ }^{7}$. However, congenital cervical spine spondylolysis is discovered by incidental radiographic finding, neck pain after minor trauma, a clunking or clicking neck and rarely neurologic compromise ${ }^{1-3,6,8,10)}$. This rare condition potentially signifies an unstable cervical spine.

We will report a case of congenital isthmic defect of cervical spine and describe a cause of cervical isthmic defect, diagnostic radiographic finding and appropriate treatment of cervical spondylolysis or spondylolithesis.

\section{CASE REPORT}

A 23-year-old female suffered from a hyperextension injury to cervical spine after a traffic accident. Following this injury, she experienced mild to moderate degree of nuchal and back pain. She had no neurological symptoms or signs. There was no history of significant illness or trauma in the past.

- Received: November 19, 2012 • Revised: February 13, 2013

- Accepted: March 7, 2013

Corresponding Author: Jeong-Wook Lim, MD

Department of neurosurgery, Daejeon Sun General Hospital, 10-7

Mok-dong, Jung-Gu, Daejeon 301-725, Korea

Tel: +82-42-220-8850, Fax: +82-42-220-8850

E-mail: magicdoctor@hanmail.net
Plain radiograph of the cervical spine showed bilateral pars interarticularis defect at the $\mathrm{C} 6$ level with cleft-bow-tie configuration, hypoplastic pedicle, grade I spondylolisthesis of C6 on C7 and spinal bifida at C6 (Fig. 1). Computed tomography of the $\mathrm{C} 6$ vertebrae showed bilateral corticated defects of the C6 articular mass, bilateral hypoplastic pedicles, lamina and spinal bifida of C6 and apparent neural foraminal enlargement at C6-7 (Fig. 2). The magnetic resonance image of spine showed grade I spondylolisthesis C6-7, degenerative change of C6-7 disc and acute compressed fracture at $4^{\text {th }}$ thoracic vertebrae. She was subjected to controlled flexion-extension views of the cervical spine, which confirmed stability of the segment with
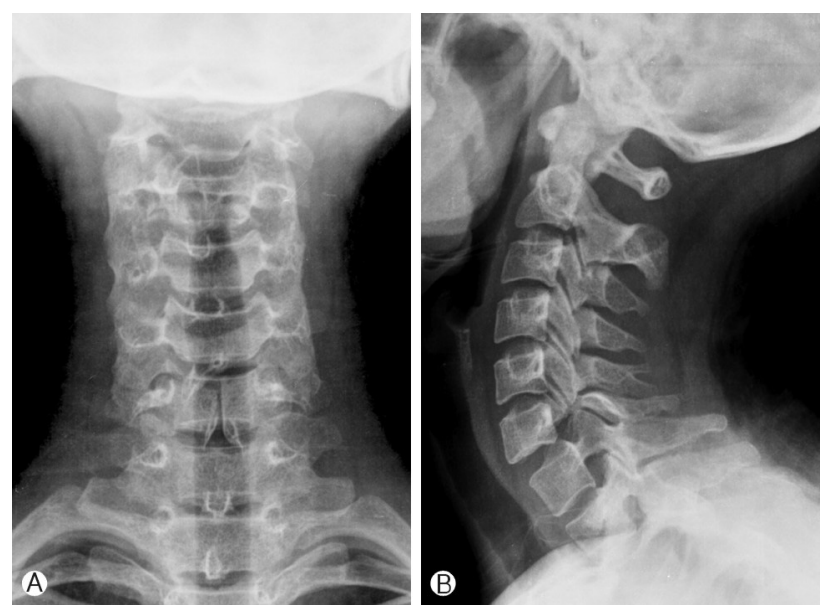

Fig. 1. Plain cenvical radiographys (A, B) show, first a corticated pedicular defect of $\mathrm{C} 6$, secondly hypoplasia of the $\mathrm{C} 6$ pedicle and grade I spondylolisthesis of $\mathrm{C} 6$ on $\mathrm{C} 7$, thirdly spinal bifida of C6. 
less than 10 degrees of anterior angulations (Fig. 3). The cervical spine was stable on lateral flexion and extension radiography.

She was treated with the semihard-orthosis brace immobilization for 8 weeks followed by repeated lateral cervical spine radiography. After 10 months to injury, she was symptom free with full range of motion of cervical spine.
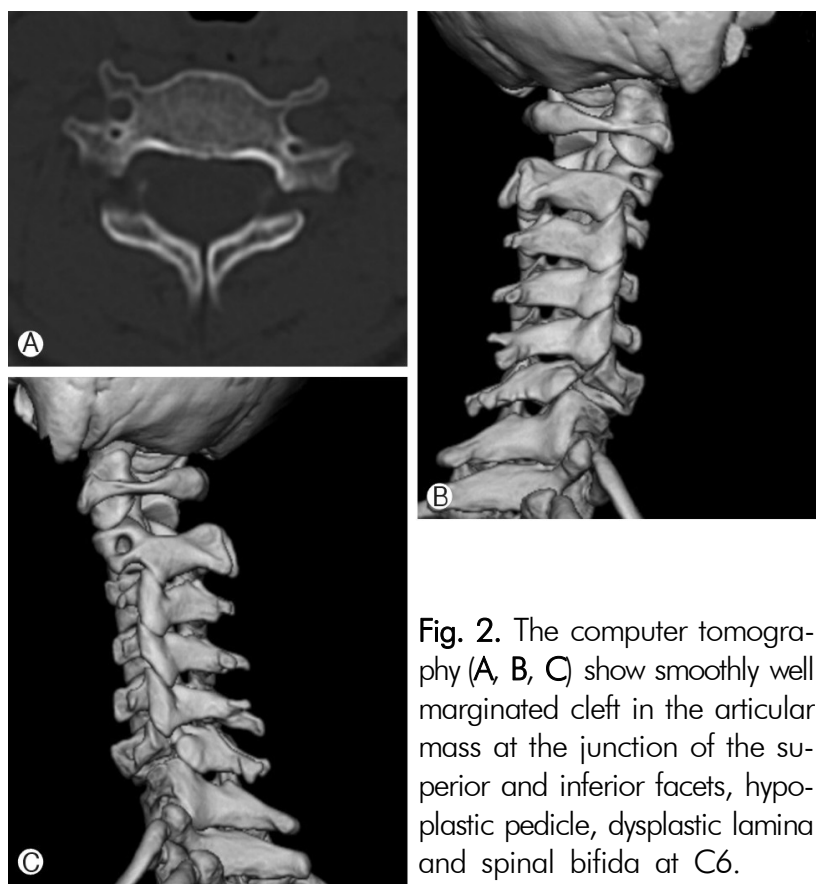

Fig. 2. The computer tomography $(A, B, C)$ show smoothly well marginated cleft in the articular mass at the junction of the superior and inferior facets, hypoplastic pedicle, dysplastic lamina and spinal bifida at $\mathrm{C} 6$.

\section{DISCUSSION}

Reported cervical spondylolysis are incidentally discovered except the "Hangman's" fracture ${ }^{1-3,6,8,9,10)}$. Cervical spondylolysis is less prevalent than lumbar spondylolysis, only about 100 cases have been reported in the literature worldwide, mainly in adults ${ }^{1}$. There is often no clear uniform mechanism of the injury, or the force causing the injury is often not strong enough to explain all of observed cervical anomaly. Incidentally discovered cervical spondylolysis could combine with another anomaly like spinal bifida, dysplastic lamina or transverse process (Table 1).
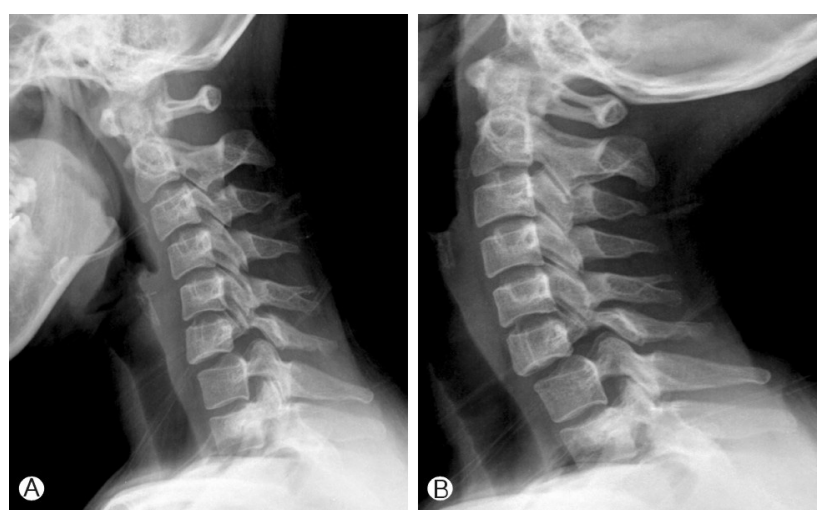

Fig. 3. Plain cervical flexion-extension radiographys (A, B) confirm stability of the segment with less than 10 degrees of anterior angulation and no anterolisthesis.

Table 1. Overviews of another cases of cervical spondylolysisincluding age of the patients, level of pathology, presence of associated spinal 1 anomalies or preceding trauma, presence of instablility, neurologic deficit and treatment

\begin{tabular}{|c|c|c|c|c|c|c|c|c|}
\hline Authors & Level & Age & $\begin{array}{l}\text { Sex } \\
(M / F)\end{array}$ & $\begin{array}{l}\text { Associated } \\
\text { pathology }\end{array}$ & $\begin{array}{l}\text { Combined spinal } \\
\text { anormalies }\end{array}$ & $\begin{array}{l}\text { Neurologic } \\
\text { deficits }\end{array}$ & Instability & Treatment \\
\hline Our case & C6 & 23 & $-/ 1$ & TA & + & none & Stable & observation \\
\hline Ahn et al. ${ }^{1}$ & C6 & $33-54$ & $2 / 1$ & & + & $\begin{array}{l}\text { 1-neck pain } \\
2 \text {-major }\end{array}$ & $\begin{array}{l}\text { 1-stable } \\
\text { 2-unstable }\end{array}$ & 3-fusion \\
\hline Choi et al. ${ }^{8}$ & C6 & 27,32 & $2 /-$ & TA & + & 2-none & 2-stable & observation \\
\hline Forsenberg et al. ${ }^{2}$ & C6 (6) & $20-80$ & $9 / 3$ & $\begin{array}{l}\text { 9- incidental } \\
\text { 3-TA }\end{array}$ & + & none & No clarification & No clarification \\
\hline Howard et al. ${ }^{3}$ & $\begin{array}{l}\mathrm{C} 1(1) \\
\mathrm{C} 2(5) \\
\mathrm{C} 4(1)\end{array}$ & $\begin{array}{l}5 \text { months } \\
\sim 14 \text { years }\end{array}$ & $4 / 3$ & $\begin{array}{l}\text { 2- trauma } \\
\text { 5- incidental }\end{array}$ & No clarification & $\begin{array}{l}\text { 1-major } \\
\text { 6-none }\end{array}$ & 2-unstable & $\begin{array}{l}\text { 3-fusion } \\
\text { 1-cast } \\
\text { 3-observation }\end{array}$ \\
\hline Morvan et al. ${ }^{6}$ & $\begin{array}{l}\text { C6 (5) } \\
\text { C4 (10) } \\
\text { Multi (1) }\end{array}$ & $19-56$ & & $\begin{array}{l}\text { 6- congential } \\
1 \text { - incidental }\end{array}$ & No clarification & $\begin{array}{l}\text { 1-major } \\
\text { 6-none }\end{array}$ & 2-unstable & $\begin{array}{l}\text { 1-decompression } \\
\text { 6-observation }\end{array}$ \\
\hline Redla et al. ${ }^{9}$ & $C(6)$ & 29,53 & $1 / 1$ & $\begin{array}{l}1-\mathrm{TA} \\
1 \text { - incidental }\end{array}$ & + & 1-severe pain & 2-stable & $\begin{array}{l}\text { 1-fusion } \\
\text { 1-observation }\end{array}$ \\
\hline
\end{tabular}

Major indicates myelopathy, minor: radiculopathy, multi: multiple level spondylolysis, TA: Traffic accident 
The etiology of cervical spondylolysis is unknown, but congenital basis is asserted because no history of trauma is elicited in the majority of cases $^{2,3,5)}$. Another basis is nonunion of vertebra after birth, infantile fracture or repetitive microtrauma ${ }^{1,6,9}$. Moore described the five secondary ossification centers that form after birth ${ }^{5)}$. The vertebral body will articulate with the vertebral arch at the neurocentral joints at birth, with fusion occurring between the ages of 5 and 8 years ${ }^{5,7}$. If congenital defect is invalid, problem of ossification or chondrification might occur during vulnerable period from birth to fusion at neurocentral joint. Morvan et al. proposed that this condition was caused by repetitive microtrauma resulting in stress fractures to the pars region similar to the process proposed in lumbar spondylolysis ${ }^{5}$. They further proposed C6 to be the commonest site to be affected as, this being a transitional vertebra, it was subjected to stress more often. Some of these theories can be put together and it may be suggested that a dysplastic spine is more susceptible to trauma or stress and leads to spondylolysis ${ }^{6}$. We could clarify that our case was associated with congenital basis because of well corticated margin in defected area combined with another congenital lesion and no trauma history. Congenital cervical spondylolysis, an embryologic developmental defect, occurs the most commonly at $\mathrm{C} 6^{1,2,6,9,10)}$. The overall frequency is unknown, and most cases are detected incidentally (Table 1)

Conventional radiolographic findings of cervical spondylolysis included a deformed articular mass, hypoplastic or dysplastic pedicle, spinal bifida and anterolisthesis ${ }^{1-3,6,8-10)}$. The computed tomography is the most useful image modality, because it shows the exact bony structures and three dimensional images. The magnetic resonance image could help to distinguish between traumatic and congenital cause ${ }^{9)}$. The magnetic resonance image can aid identification of combined soft tissue damage, cord injury and bony contusion at trauma lesion. However, magnetic resonance image is not useful for diagnosis of cervical spondylolysis. In our case, cervical magnetic resonance image showed acute compressive fracture at $4^{\text {th }}$ thoracic vertebrae and degenerative disc change.

Misdiagnosis occurred for traumatic unilateral interfacet dislocation, a chronic nonunited articular mass fracture or congenitally absent pedicle ${ }^{4,10)}$. These disease entities could be distinguished by computer tomography. For example, unilateral interfacet dislocation is characterized by spondylolisthesis greater than $3 \mathrm{~mm}$, rotation without a superimposed articular mass, and misalignment of the spinous process ${ }^{4}$.

The cervical spondylolysis can cause variable symptoms like neck pain, muscle spasm or neurologic deficit. Symptomatic cervical spondylolysis need adequate treatment because previously existing cervical spondylolysis is vulnerable to trauma.

The treatment of cervical spondylolysis depends on instability. If the cervical spine is stable, conservative approach is desirable for treating symptomatic cervical spondylolysis. If it is in unstable status, surgical fixation can be needed. Our case was stable but needed hard orthosis because of the fracture of $4^{\text {th }}$ thoracic vertebrae.

\section{CONCLUSION}

Cervical spondylolysis is a very rare condition. Its clinical importance is vulnerability to trauma. The etiology of cervical spondylolysis is still a controversy. Computer tomography and plain film are useful diagnostic image modality.

For whatever reasons, symptomatic patients need to be treated by conservative or surgical option. Giving more attention to cervical spondylolysis will help further exact diagnosis and appropriate therapy.

\section{REFERENCES}

1. Ahn PG, Yoon do H, Shin HC, Kim KN, Yi S, Lee DY, et al: Cervical spondylolysis: three cases and a review of the current literature. Spine 35(3):E80-3, 2010

2. Forsberg DA, Martinez S, Vogler JB 3rd, Wiener MD: Cervical spondylolysis: imaging findings in 12 patients. AJR Am J Roentgenol 154:751-755, 1990

3. Howard AW, Letts RM: Cervical spondylolysis in children: Is it posttraumatic? J Pediatr Orthop 20:677-681, 2000

4. Kalacyi M, Cagavi F, Acikgoz B: Unilateral cervical facet fracture: presentation of two cases and literature review. Spinal Cord 42:466-472, 2004

5. Kaplan KW, Spivak JM, Bendo JA: Embryology of the spine and associated congenital abnormalities. Spine J 5:564-576, 2005

6. Morvan G, Busson J, Frot B, Nuhum H: Cervical spondylolysis. 7 cases. review of the literature. J Radiol 65:259-266, 1984

7. Parisi M, Lieberson R, Shatsky S: Hangman's fracture or primary spondylolysis: a patient and a brief review. Pediatr Radiol 21:367-368, 1999

8. Choi YM, Han YM: Cervical spondylolysis: report of two cases. J Korean Neurosurg Soc 36(4):337-379, 2004

9. Redla S, Sikdar T, Saifuddin A, Taylor BA: Imaging features of cervical spondylolysis --with emphasis on MR appearance. Clin Radiol 54:815-820, 1999

10. Sheehan J, Kaptain G, Sheehan J, Jane J Sr: Congenital absence of a cervical pedicle: report of two cases and review of the literature. Neurosurgery 47:1439-1442, 2000 